\section{A CASE OF DIAPHRAGMATIC HERNIA.} [With Special Plate.]

BY

GEORGE J. LANGLEY, M.D., M.R.C.P., PHYSICIAN ANCOATS hospital, MANCHESTER.

Tith Surgical Notes by JoHN MorLey, CH.M., F.R.C.S., and Radiological Notes by J. M. WoodBURN Morison, M.B., C.M., of the same Hospital.

A LARGE number of these cases are now on record, but they still rank as pathological curiosities. They may be divided into several groups, which are very distinct :

(a) Traumatic cases, of which the war has provided a regrettably large number.

(b) True diaphragmatic hernia arising from a congenital defect in the diaphragm, through which abdominal content herniates.

(c) Eventration, in which there appears to be a con. genital weakness of the diapliragm and consequent dislocation of related abdominal viscera.

The following case illustrates the difficulties of accurate diagnosis and of selecting the best method of treatment.

A schoolgirl, aged 10 years, was brought to hospital, having had a cough and cold for two weeks. There were eight other children in the family, all healthy and well. 'The mother had had one miscarriage, and one child had died at the age of 12 months from zymotic enteritis.

The patient had never been robust, but the only serious illness cccurred when, at 2 years of age, she developed morbilii followed by pneumonia. The child had been to hospital on three or more previous occasions for trivial ailments, but in spite of this had lost very little time from schcol. The only present complaint was of cough and cold. At no time had there been any reason to suppose that the gastro-intestinal tract was other than normal.

Routine examination resulted as follows :

The child is small and thin, with normal colour and no deformities. The chest is poorly covered, the ribs being easily visible and respiratory movement normal. The area of cardiac dullness, position of apex beat, and heart sounds were normal, and no extension of dullness to the right was found. The pulse was good.

The right lung appeared healthy, but on the left side an area of dullness to percussion was found, extending downwards from the fifth rib in the nipple line, eighth space in the anterior axillary live, and angle of the scapula behind. Over this area vocal resonance and fremitus were almost absent, while breath sounds were diminished but normal in character, with no adventitious sounds. In the abdomen the liver dullness extended from the sixth rib to the costal margin, where its edge could be felt; the spleen could also be felt, its dullness being merged in that above described.

No other abnormality was found beyond the fact that the pupils, though fully active, were not quite equal, the left being slightly larger than the right.

While under observation it was found that the upper limit of percussion dullness over the left lung was variable, being sometimes a rib or space lower than that above described. Hippocratio succussion and the coin sound could sometimes be obtained. At no time during observation were there any symptoms pointing to the digestive tract.

Dr. Morison, radiologist to the hospital, made repeated examinations of the chest at all stages of digestion, and the following is a condensed report of his tindings:

The screen examination of the chest showed a complete regular dome on the left side, extending as high as the level of the third rib in front, and enclosing an air space through which in the upper part lung tissue was seen. At the bottom of this air space there was a sharply defined horizontal line of fluid on which waves and ripples were produced by palpation of the abdomen.

No definite movements of the bow liue in the chest were observed during respiration, although on one occasion I thought thers was a slight reversed movement (an upward movement during inspiration and a downward during cxpiration), but I was not quite confident of this.

The dome of the right diaphragm was at the level of the tenth dorsal vertebra. Its movements were normal. The heart was slightly displaced to the right. There was an increased density of the root shadows of both lungs.

On giving a bismuth meal the food was held up at the cardiac opening of the oesophagus, the lower third of which was dilated, the obstruction was soon overcome, and the stomach was seen to fill in an irregular manner. The cause of this was apparent when the patient, who up to this stage had been examined in the postero. anterior position, was placed in the right anterior oblique positiou. There were two sacs, the shadows overlapping in the costero-sinterior position. The upper sac, when filled, spilled in a lorward direction into the lower. The pyloric end of the stomach was directed backwards, and was not well formed. There was no delay in emptying.

In the lying-down position the bismuth meal passed up to the top of the bow line in the chest, displacing the air, and completely filling the dome, which was not altered in position. Nothing abnornal was detected -jn the small intestine. The colon was well outlined, and the sp!enic tlexure was found to rise alongside the air cap of the stomach to the top of the bow line in the chest, but not beyondit. At other times the whole of the dome in the chest was filled by the air cap of the stomach.

A barium enema confirmed these observations on the colon, which was otherwise normal.

It soon became apparent that in this case the determining factor was the $x$-ray finding, and tirat it was the only possible means of differentiating the genuine hernia from an eventration.

The difficulty in the case largely lay in the fact that the patient had come under observation in the absence of symptoms, whereas so many of the other recorded cases had been acutely ill or had shown active gastric symptoms.

It was finally determined that the case was most probably one of true congenital diaphragmatic hernia, and that these cases usually did not come under observation until some acute condition, as volvulus or strangulation, had occurred. 'The proguosis was then extremely bad, and it was decided that for tliese reasons it were wiser to operate under quiet conditions and so prevent the onset of these more serious symptoms.

Mi: John Morley, surgeon to the hospital, was therefore asked to see the case, and operation was undertaken. It had been previously determined that the function of the stomach as regards acid and pepsin was normal, or at least that part of it from which the test meal was recovered.

Operation took place on February 19th, 1920; gas and oxygen with ether were administered by Dr. K. B. Pinson.

It was decided to perform thoracotomy in the first place, as it was considered that this would facilitate reduction of the herniated viscera through the diaphragm by affording more direct access. Accordingly, with the patient in the right lateral position, an incision five inches long was madealong the eighth left rib, with its centre in the posterior axillary line. The rib was resected to the extent of four inches and the pleura opened. The ribs abcre and below were retracted widely by Tuffier's rib spreader.

The fundus of the stomach could now be seen projecting up into the thorax far above the level of the incision. It was at once apparent that a transparent layer of thinned-out diaphragm apparent that a transparent layer of thinned-out diaphragm separated them completely from the true pleural cavity, which was greatly reduced in size. To the highest point of this thin translucent diaphragm the base of the left lung was firmly adherent. These adhesions were fibrous and vascular and were readily divided. The diaphragmatic sac was now incised. On opening it the splenic flexure of the colon and left extremity of the great omentum and greater curvature of the stomach were presented. These were quite free from adhesions. The upper pole of the spleen also came into view.

It was now p!ain that there was no functioning diaphragmatic muscle at all, but that the whole diaphragm was merely represented by a thin sheet consisting of pleura above and peritoneum below, with some rather dense fibrous tissue between. A partial excision of this diaphragmatic sac was determined tipon. with the object of bringing down its level as near to the normal as possible, and so reducing the distortion of the stomach and allowing more expansion of the lung.

The opening in the sac, therefore, was enlarged backwards with scissors towards the posterior aspect of the heart, and an elliptical strip of thinned-out diaphragm removed. The abdominal viscera were now packed downwards, so as to remove upward pressure on the sac, and the rent in the sac was sutured with two layers of catgut in such a manner as to overlap the edges broadly and so reduce the diaphragmatic level. When this was completed the dome of the diaphragm reached to the seventh rib in the midaxillary line. After wiping blood clots from the pleura the rib spreader was removed and the pleura and intercostal muscles spreader was removed and the pleura and intercostal muscles skin were then sutured in layers.

The patient took the anaesthetic well, but the pulse became very rapid during the suturing of the d:aphragm and reached a maximum

Convalescence was uneventful and rapid. There was considerable pain on respiration for the first few days, but it was noticeable that no pain was felt at the usual site of referred painfrom the phrenic nerve-the tip of the left shoulder

Microscopical sections of the piece of diaphragm removed showed
inger normal endothelium on the pleural and peritoneal surfaces, and between these dense fibrous tissue, with no sign of muscle fibres. No nerve fibres could be made out in sections that were specially
stained to show them.

The subject of non-traumatic hernia of the diaphragm was discussed by Scudder ${ }^{1}$ in 1912 , who stated that up to that date 1,000 cases had been reported, most of. which were discovered post mortem; 53 operations had been performed. of which 11 were thoracotomies, with 7 recoveries and 4 deaths. and 42 were explored by an abdominal incision. 

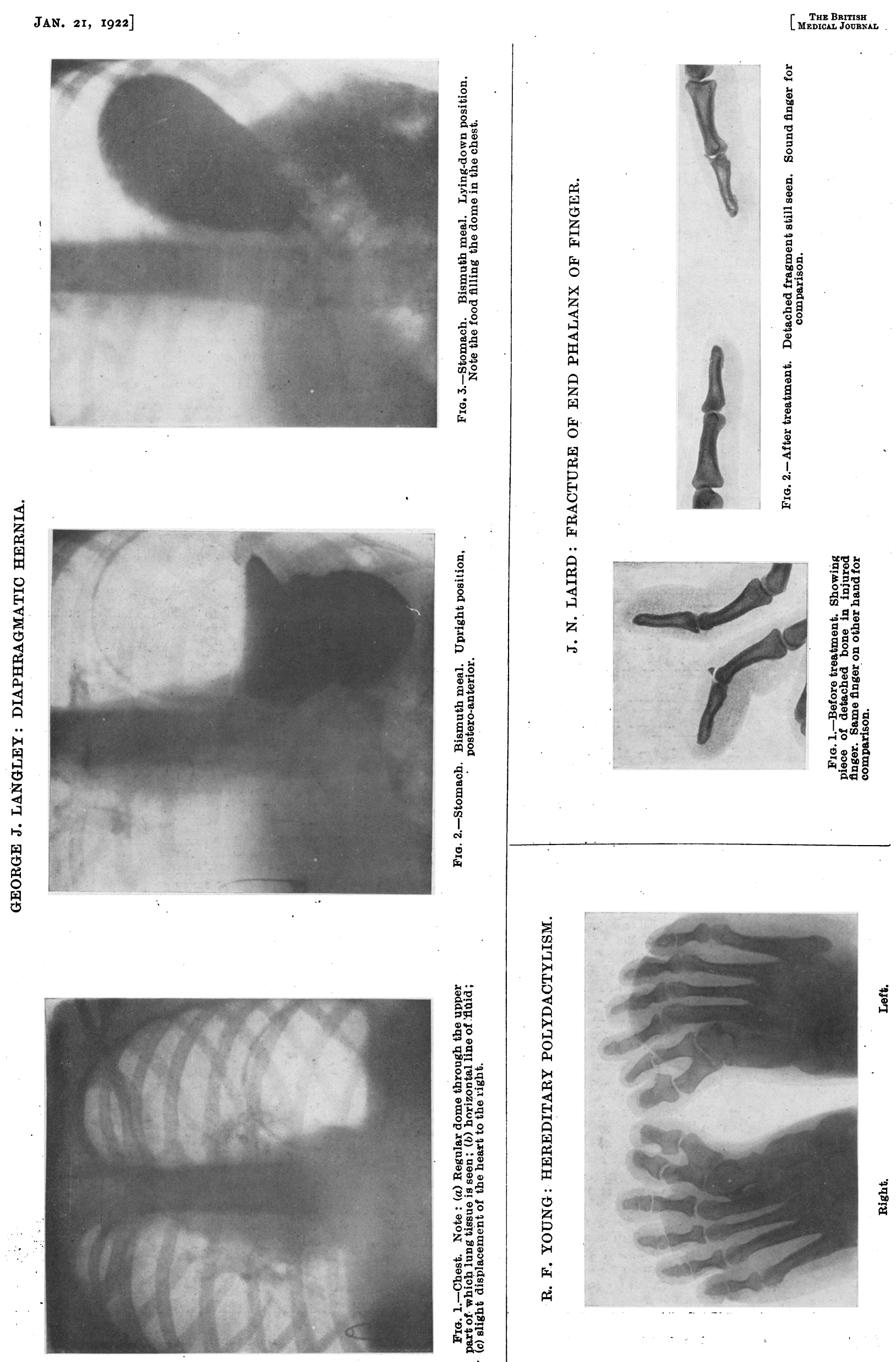
with 7 recoveries and 35 deaths. The diagnosis was made beforehand in only six cases. Operation was usuaily performed for acute intestinal obstruction.

Giffin, ${ }^{2}$ writing in 1912, and discussing the differential diagnosis between congenital hernia of the diaphragm (witl prolapse of viscera through a gap in the diaphragm) and congenital elevation or eventration of the diaphragm, enumerates certain skiagraphic features which, he considers, help to differentiate the two conditions.

Giffin considers that: (1) A dome-shaped outline of the diaphragm is invariable in congenital elevation, whereas the shadow of the diaphragm may be irregular in hernia. (2) Mottled lung tissue may be seen through the clear area in the thorax in cases of liernia, but not in cases of elevation. (3) If the colon be found extending up into the chest and beyond the bow line, the case is one of true hernia. (4) Paradoxical respiratory displacement in which the affected side, usually the left, moves up on inspiration and down on expiration, is found usually in hernia. In congenital elevation the movements of the diaphragm are normal, though of reduced range.

Our study of the present case would appear to disprove much of this. Thus we found that mottled lung tissue could be seen through the clear area below the dome formed by the shadow of the dianphragm; the splenic flexure of the colon projected high up into the thorax, and although reversad diaphragmatic movement was doubtful before operation, yet it became well marked after the operation, and this although the diaphragmatic bow line was at a lower level.

The recognized nomenclature of these conditions is hardly satisfactory. Custom has decreed that cases of congenital defect or gap in the diaphragm, with prolapse of viscera into the pleural cavity through that gap; should be labelled "hernia," although the hernia possesses no sac ; whereas to cases such is the one we now report, in which the thinned-out diaphragm forms a veritable sac, the term "heinia" is denied. It must be admitted, however, that to alter the terminology now would be to lead to considerable confusion.

The etiology of congenital elevation of the diaphragm remains obscure. The appearance of our histological preparations suggests that the intermediate fibrous tissue was essentially degenerated and fibrosed muscle, and: this would suggest a congenital absence or lesion of the left phrenic nerve, and in this connexion the inequality of the pupils is interesting.: But this does not carry us very far, since we are without a clue as to the cause of the nerve lesion.

The condition cannot be ascribed to a failure in the descent of the diaphragm, since the skeletal attachments of that muscle at its periphery were found to be perfectly normal, and its great eleration was plainly due to its intrinsic weak. ness and inability to withstand the upward thrust of the abdominal viscera.

A farther radiological examination in this case, four weeks after the operation, showed that the collapsed lung had com. pletely expanded. There was considerable thickening of the shadow cast by the bow line in the chest, and now paradoxical movements of the diaphragm were seen, the bow line in the chest descending during expiration and ascending during in spiration, while the morements on the right side vere normal. The examination of the stomach now showed that the two sacs were no longer present. Three months later.examination showed that adhesions were beginning to form, the movements of the bow line in the chest being now greatly restricted though still reversed.

\section{Conclusions.}

It would appear from this case that:

(a) Physical signs at the base of the left chest may be sufficiently well marked in diaphragmatic hernia to make tho differential diagnosis from subphrenic abscess and pyopncumothorax a matter of considerable difficulty.

(b) Ultimate diagnosis must remain in the hands of the radiologist, but the points which inave in the past been regarded as valuable in differentiating true hernia from eventration cannot be entirely relied upon.

(c) In the light of recorded cases and the ultimate acute abdominal condition which may, and probably will, superverte, "exploration is desirable in these cases, unless it can be conclusively proved that the case is one of simple eventration.

\section{REFERENCEs.}

${ }^{1} \mathrm{C}$. L. Scudder. Stirgery, Gyuecology, and Obsteirics, vol, xv, 1912 ₹6:-267. 2 H.Z. Giffn, Annals of Surgery, vol. $1 \mathrm{v}, 1912,388-397$.

\section{HEREDITARY POLYDACIYLISM.}

\section{[With Special Plate.]}

BY

ROY F. YOUNG, B.A., M.B., B.Ch.,

ASSISTANT SURGEON, WESTERN INFIRMARY, GLASGOW.

THE following case of bilateral double great toe presents some points of interest, more particularly from the operative point of view.

The genealogical table is very incomplete, and can only be traced to the grandfather of this patient. Prior to him it is reported that accessory toes have "descended down, but was a matter which was never discussed." The only deformity has been that of additional toes.

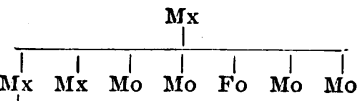

Mx Fx $^{\prime}$ Mo

$\mathbf{M}=$ Male $; \mathbf{F}=$ Female; $*=$ Patient $; \mathbf{x}=$ Deformily $; o=$ No deformity.

With regard to the pathology, the $x$-ray appearance (see plate) confirms the opinion that the accessory digits are due to fission. On the right foot the proximal phalanges were fused for half their length ; there is also incomplete fission of the metatarsal. On the left foot the separation of the phalanges was complete; the $x$-ray appearance also suggests that the more external or lateral toe is the more rudimentary.

\section{Operation.}

After due consideration it was decided to remove the medial too on the right foot and the lateral toe on the left. The reasons for the latter choice were the distinctly more rudimentary nature of the lateral toe on the left foot, and that the resulting scar would be less liable to pressure from the boot. On the other hand, by removal of the medial toe better alignment could be secured. Further, it was of value to discover which method gave tho more satisfactory result.

The result was very convincing. The patient was seen two montlis after operation. The right foot was completely satisfactory in use and appearance, and there was no irritation from the scar. The left font was found much as before operation. Thrce months later the left foot had improved considerably, both in use and in appearance, but at the end of a day's work it felt very tired. A year after operation the left foot was still less satisfactory than the right.

I have to express my thanks to Dr. Duncan Macartney, in whose ward I treated this case.

\section{THE CARELLI METHOD OF PERIRENAL INFLATION.}

An Account of a Recent Demonstration at THE FRENCH Hospital.

[With Special Plate.]

$\mathbf{B Y}$

F. HERNAMAN-JOHNSON, M.D.,

Director of the $X$-ray and Electrical Skrtice, the French hospital, London; Peysicia margaret Stheet hospital for Consumption.

A short time ago Dr. F. G. Crookshank, physician to the French Hospital, while visiting Paris, was talren by Dr. André Leri to see a demonstration on pneumopcritoneum and the inflation of certain tissues, by Dr. Carelli of Buenos Aires. He was greatly impressed by the beautiful examples shown of gall-bladder disease, adhesions, cystic ovaries, Fallopian tube disease, and of pregnancy diagnosed at one month owing to the small but uniform increase in size of the uterus being made visible. What struck him most, however, was the entirely new procedure of perirenal inflation, an idea the carrying out of which is due to Dr. Carelli.

Dr. Carelli has demonstrated his methods in Berlin and Vienna, and is about to do so in the United States. Dr. Crookshank urged liim to visit London, and he consented, though at considerable personal inconvenience. It was arranged that he should give an account of his methods at the Royal Society of Medicine, and I was asked to place my department at his disposal for an actual demonstration of 